\title{
Cognitive control associated with irritability induction: an autobiographical recall fMRI study
}

\section{Controle cognitivo associado à indução de irritabilidade: um estudo de RMf usando recordações autobiográficas}

\author{
Carlos T. Cerqueira, ${ }^{1}$ Jorge R. C. Almeida, ${ }^{1}$ João R. Sato, ${ }^{2,3}$ Clarice Gorenstein, ${ }^{1}$ Valentim Gentil, ${ }^{1}$ Claudia C. \\ Leite, ${ }^{2}$ Edson Amaro Jr, ${ }^{2}$ Geraldo F. Busatto ${ }^{1,2}$ \\ ${ }^{1}$ Department of Psychiatry, School of Medicine, Universidade de São Paulo (USP), São Paulo, SP, Brazil \\ 2 Department of Radiology, School of Medicine, Universidade de São Paulo (USP), São Paulo, SP, Brazil \\ ${ }^{3}$ Center of Mathematics, Computation and Cognition, Universidade Federal do ABC, Santo André, SP, Brazil
}

\begin{abstract}
Objective: Despite the relevance of irritability emotions to the treatment, prognosis and classification of psychiatric disorders, the neurobiological basis of this emotional state has been rarely investigated to date. We assessed the brain circuitry underlying personal script-driven irritability in healthy subjects $(\mathrm{n}=11)$ using functional magnetic resonance imaging. Method: Blood oxygen level-dependent signal changes were recorded during auditory presentation of personal scripts of irritability in contrast to scripts of happiness or neutral emotional content. Self-rated emotional measurements and skin conductance recordings were also obtained. Images were acquired using a 1,5T magnetic resonance scanner. Brain activation maps were constructed from individual images, and betweencondition differences in the mean power of experimental response were identified by using cluster-wise nonparametric tests. Results: Compared to neutral scripts, increased blood oxygen level-dependent signal during irritability scripts was detected in the left subgenual anterior cingulate cortex, and in the left medial, anterolateral and posterolateral dorsal prefrontal cortex (cluster-wise p-value $<0.05$ ). While the involvement of the subgenual cingulate and dorsal anterolateral prefrontal cortices was unique to the irritability state, increased blood oxygen level-dependent signal in dorsomedial and dorsal posterolateral prefrontal regions were also present during happiness induction. Conclusion: Irritability induction is associated with functional changes in a limited set of brain regions previously implicated in the mediation of emotional states. Changes in prefrontal and cingulate areas may be related to effortful cognitive control aspects that gain salience during the emergence of irritability.
\end{abstract}

Descriptors: Emotion induction; Mood disorders; Neurobehavioral manifestations; Neuroimaging

\section{Resumo}

Objetivo: Apesar da relevância de emoçôes de irritabilidade para o tratamento, prognóstico e classificação dos transtornos psiquiátricos, as bases neurobiológicas deste tipo de estado emocional foram raramente investigadas até hoje. Este estudo avaliou os circuitos cerebrais subjacentes à irritabilidade induzida por scripts pessoais em voluntários saudáveis $(n=11)$ usando ressonância magnética funcional. Método: Mudanças no sinal dependente do nivel de oxigenação sanguinea (blood-oxygen level dependent signal) foram registradas durante a apresentação por via auditiva de scripts pessoais de irritabilidade em contraste com scripts de felicidade ou de conteúdo emocional neutro. Escores em escalas de autoavaliação emocional e medidas de condutância da pele também foram obtidos. A aquisição de imagens foi realizada em aparelho de ressonância magnética de 1,5 T. Os mapas de ativação cerebral foram construidos a partir das imagens individuais, e as diferenças entre as condiçôes experimentais foram investigadas utilizando testes não-paramétricos baseados em permutaçôes. Resultados: Em comparação com scripts neutros, a apresentação de scripts de irritabilidade levou a aumentos de sinal dependente do nivel de oxigenação sanguinea na porção subgenual do giro do cíngulo anterior esquerdo e nas porçôes medial, ântero-lateral e póstero-lateral do córtex pré-frontal dorsal (cluster-wise p-valor $<0,05$ ). Enquanto o envolvimento do cingulo anterior subgenual e do córtex pré-frontal dorsal antero-lateral surgiu apenas em associação com o estado de irritabilidade, aumentos do sinal dependente do nível de oxigenação sanguínea nas porçôes dorso-medial e dorsal póstero-lateral do córtex pré-frontal também estiveram presentes durante indução de felicidade. Conclusão: Indução de irritabilidade está associada a mudanças de atividade funcional num conjunto restrito de regiōes cerebrais previamente implicadas na mediação de estados emocionais. Mudanças na atividade de porçôes do giro do cíngulo e pré-frontais podem estar relacionadas a esforço de controle cognitivo associado à expressão de emoçōes de irritabilidade.

Descritores: Indução de emoçôes; Transtornos do humor; Manifestações neurocomportamentais; Neuroimagem
Submitted: December 23, 2008

Accepted: August 15, 2009

\section{Correspondence}

Carlos Toledo Cerqueira

Departamento de Psiquiatria - Faculdade de Medicina -

Universidade de São Paulo

Centro de Medicina Nuclear

Rua Ovídio Pires Campos, s/n

05403-903 São Paulo, SP, Brazil

Phone/Fax: (+55 11) 3082-1015

E-mail: carlostclabneuropq@hotmail.com 


\section{Introduction}

Several imaging studies in healthy human subjects using positron emission tomography (PET) or functional magnetic resonance imaging (fMRI) have been conducted during the provocation of specific emotional states, including happiness, sadness, fear, anger, anxiety, guilt or disgust. These studies have demonstrated the involvement of multi-focal brain circuits in emotional processing, frequently involving portions of the frontal and temporal neocortices, anterior cingulate gyrus, medial temporal structures, amygdala, insula and the basal ganglia. ${ }^{1-4}$ Despite the wealth of such literature on emotional processing, not all kinds of human emotions have as yet been investigated using functional imaging techniques. For instance, no imaging study to date has assessed the neural circuits involved specifically in the mediation of irritability states. Irritability is a distinct negative emotional state that involves a subjective reduction in the control over temper in response to sensorial or psychic stimuli. ${ }^{5,6}$

Classic conceptualizations differentiate irritability from anger by the absence, in the former, of the actual intention to hurt. ${ }^{7}$ Other authors have emphasized irritability as a broader construct than anger, involving a greater range of behavioral, and in particular cognitive, features. Such cognitive aspects may be critical to the management of feelings of irritability in ways other than through the expression of aggression. ${ }^{6,8}$

Irritability emotions may appear either in healthy individuals ${ }^{9,10}$ or in the context of psychiatric conditions including mood disorders, substance misuse disorders and borderline personality disorder. ${ }^{11}$ In particular, irritability is highly prevalent in major depressive disorder, and is associated with greater severity of depression, suicidal tendencies, and impairments in overall functioning. ${ }^{12}$ Irritability emotions are also a frequent feature of bipolar spectrum disorders, particularly in association with younger age, presence of other axis I psychiatric conditions, atypical depressive features and mixed mood states. ${ }^{13,14}$ Such data suggest that irritability is relevant not only in terms of the prognosis and treatment planning for mood disorders, but may also be a potential marker of nosological subtypes of these conditions. $^{14}$

We have recently devised an fMRI protocol aimed at detecting brain activity patterns associated with the induction of emotional states by presentation of autobiographical scripts. Using this type of paradigm in a group of 11 healthy volunteers, we recently reported significant foci of activation in the prefrontal cortex, insula, dorsal anterior cingulate cortex, thalamus, hypothalamus and middle temporal gyrus during auditory presentation of happiness scripts. ${ }^{15}$ We describe here the specific changes in brain activity provoked by induction of irritability states using this paradigm, both in comparison to presentation of neutral or happiness-inducing personal scripts. By delineating the brain circuitry involved in the normal experience of irritability, we aimed to provide clues that may help in the future elucidation of the neural basis of pathological irritability states associated with psychiatric disorders. In accordance with the categorization of irritability as an emotional state of negative valence, we predicted the engagement of brain regions previously implicated in the expression of negative emotions, including the ventral prefrontal cortex, subgenual anterior cingulate cortex and insula. ${ }^{1,2,16}$ In addition, given the proposed prominence of cognitive aspects in the processing of irritability, we aimed to verify whether the irritability state would necessarily involve the anterior cortical brain regions previously implicated in the effortful cognitive regulation of emotion, including the dorsomedial and dorsolateral prefrontal cortices, and the dorsal anterior cingulate gyrus. ${ }^{2,4}$

\section{Method}

\section{Participants}

We studied eleven healthy subjects ( 5 females, 6 males), aged $21-50$ years $($ mean age $=32.4, \mathrm{SD}=7.2$ ), all right-handed according to the Edinburgh Handedness Inventory, ${ }^{17}$ and who had completed at least elementary school (mean number of years of education $=10.5, \mathrm{SD}=1.0$ ).

Subjects were recruited through newspaper and radio advertisements, and were screened by a team of psychiatrists using the following exclusion criteria: current or previous history of neurological and/or general medical conditions, as assessed by non-structured clinical interviewing, physical examination, electrocardiogram and blood and urine tests; current or previous history of psychiatric disorders including substance abuse or dependence, according to Diagnostic and Statistical Manual of Mental Disorders criteria, ${ }^{11}$ based on information obtained with the Structured Clinical Interview for DSM-IV; ${ }^{18}$ first-degree family history of psychiatric disorders including psychosis, recurrent mood disorders and dependence, using the Family History Screen; ${ }^{19}$ current use of other drugs with potentially psychoactive effects; and for female subjects, history of pregnancy or lactation within the last six months.

The Ethics Committee of the Universidade de São Paulo Medical School approved the study (Process number 048/01), and written informed consent was obtained from all subjects.

\section{Interview for the selection of personal experiences and preparation of scripts}

Within two weeks of fMRI scanning, subjects were interviewed by one of the researchers (C.T.C.) with the purpose of obtaining information for the later construction of one minute-long autobiographical scripts eliciting feelings of either irritability or happiness, as well as control scripts of neutral emotional content (three scripts for each emotional category).

A list of situations that could potentially be associated with the feeling of irritability (e.g. waiting in long queues, dealing with bureaucracy, traffic jams) was presented, prepared based on the Hassles and Uplifts scale ${ }^{20}$ and the Buss-Durkee Hostility inventory. ${ }^{5}$ Subjects were asked to recall episodes of their lives involving those situations within the past six months, and to select the emotion most intensely felt, from a list including irritability, fear, anxiety, sadness, frustration and anger/aggressiveness (with 
the latter emotion attested by the presence of an "intention to hurt" someone physically or morally). ${ }^{7}$ The personal events in which irritability was the main emotion recalled were then selected, and subjects were asked to give ratings from 1 to 10 , in each of those events, for the degree of irritability experienced (mean $=7.5$, sd $=1.8$ ), as well as for other negative emotions that might have also been felt (including anger/aggressiveness, sadness, disgust, fear). Personal episodes in which any of the additional negative emotions were rated as more severe than the irritability scores were discarded. Episodes for which subjects gave ratings greater than 1 for the presence of anger/aggressiveness were also excluded. After applying those criteria, the three remaining situations that showed the highest scores for irritability were selected.

In order to allow the selection of three personal experiences for the preparation of the happiness scripts, subjects were asked to recall previous events (within the last 6 months) in which they experienced feelings of happiness, prompted by examples of situations such as festivities, personal achievements, birth of new family members etc. For all situations chosen by the subjects, they were asked to give ratings from 1 to 10 for the degree of happiness experienced (mean scores $=9.0, \mathrm{sd}=1.2$ ), as well as to the above emotions of negative valence. We excluded episodes in which there were associated negative emotions. ${ }^{21}$ The same procedure was repeated in order to allow the selection of three emotionally neutral personal events, in order to provide information for the control scripts. None of the emotions above were self-rated as being present in association with the selected neutral situations by any of the subjects.

Finally, the interview was also used to select general contextual or conceptual subject matter from local newspapers, magazines and internet sites, rated by the subjects as emotionally neutral to them. This information was used in the construction of nine nonpersonal texts for each subject, in addition to the nine personal scripts. During the fMRI session, these neutral, non-personal texts were presented in auditory form preceding the presentation of each of the nine personal scripts. This strategy was aimed at helping to dissipate the previous emotional reaction elicited by the presentation of the personal scripts.

A high level of visual imagery capacity is desirable for an individual to be able to display prominent emotional reactions during recall of autobiographical events. Therefore, at the beginning of the interview, the Vividness of Visual Imagery Questionnaire, translated from its Spanish version, ${ }^{22}$ was given to all subjects, in order to provide a measure of their capacity for visual imagery. The current sample presented with a mean score of 31.9 ( $\mathrm{sd}=11.4)$, which indicates a good capacity for visual imagery. ${ }^{22}$

The nine personal scripts for each subject were written in the second person, using the present tense, ${ }^{23}$ by a professional writer. A predetermined text structure was employed, dividing each script into three separate paragraphs, describing respectively: the sensorial context in which the experience developed; the temporal, personal and interpersonal contexts; and the details of the emotional reaction elicited. Each paragraph was written with $40( \pm 4)$ words and $240( \pm 30)$ characters (including spaces). Scripts were read by a professional narrator of the same gender as the subject, in a normal tone of voice, ${ }^{21}$ and were recorded digitally. Audio editing of scripts was conducted using Protus ${ }^{\circledR}$ software in order to adjust the duration of each paragraph to 20 seconds without distortions ( 60 seconds for the entire script), and to a mean volume of $46 \mathrm{~dB}$, after normalization.

\section{Emotion induction procedure}

Before scanning, room lights were turned down, and auditory instructions were provided while subjects lay down on the scanner bench. The fMRI data acquisition was conducted during the presentation, via non-magnetized earphones (Commander-XG ${ }^{\circledR}$, Resonance Technology, Los Angeles, USA), of the three kinds of autobiographical scripts (irritability, happiness, and neutral emotional content). Subjects were asked to keep their eyes open and pay attention to the content of each script, recalling the emotions felt during the situation as if it was occurring at the moment of the fMRI scanning; ${ }^{24}$ they were also instructed to avoid thinking about other memories not specifically cited in the scripts. Three separate runs were performed, each including different scripts of irritability, happiness and neutral content.

The scanning session comprised three functional runs, involving scripts of irritability, happiness and neutral content. A functional run included three trials of 80 seconds, preceded by a baseline period of no stimulation ( 80 seconds). Trials were composed of a non-personal script (20 seconds) and a personal script (60 seconds). Non-personal scripts were used to dissipate the previous emotional reaction. In each run, irritability and happiness trials were presented either first or last relative to the neutral script, which was always presented in the mid-position. The position of the two emotional scripts was inverted in the subsequent runs. Also, the order of presentation of the irritability or happiness scripts in the first run (and the subsequent ones) was counterbalanced across subjects. These strategies were used to avoid a beginning-to-end bias of emotional processing for one of the two affective states (irritability or happiness).

Subjective ratings of five different emotions (happiness, irritability, sadness, fear and anxiety) were obtained immediately after the presentation of each personal script (in pseudorandomized order), as well as after the initial baseline period. Responses were provided using a set of purpose-built conductors previously installed, with velcro, on the ventral face of each of the five fingertips of the right hand. For each visual scale, subjects chose a rating from 1 (not at all) to 4 (high), by pressing the conductor placed on the thumb to one of the four conductors on fingertips 5, 4, 3 or 2, respectively. This apparatus was used in order to speed up the process of response selection and to minimize errors. A desktop computer recorded subjects' choices and response times, with its screen displaying to the examiners the same scales as those seen by subjects. In four subjects, visual scales were projected on a screen and they were visualized by the supine 
participant using a mirror mounted on the head coil of the fMRI scanner, at a distance of $390 \mathrm{~cm}$ from the projection screen. In the remaining seven subjects, scales were displayed using goggles with binocular vision (MRIVision2000 ${ }^{\circledR}$, Resonance Technology, Los Angeles, USA), worn from the onset of the fMRI examination.

Immediately before and after image acquisition, subjects responded to the State scale of the State-Trait Anxiety Inventory (STAI) ${ }^{25}$ in order to determine the levels of state anxiety across the scanning procedure. This assessment was aimed at investigating whether there would be differences in the degree of state anxiety before and after the fMRI procedure that might influence the BOLD signal patterns detected across the three functional runs.

\section{Image acquisition}

For each run (including baseline, emotional/neutral personal scripts, subjective scales and neutral non-personal scripts), a total of 220 gradient-echo T2* echo planar imaging (EPI) sets were obtained using a GE LX-MR 1.5T scanner (General Electric, Milwaukee WI, USA), each consisting of 15 interleaved non-contiguous $3 \mathrm{~mm}$-thick transaxial slices, parallel to the intercommisural line. Imaging parameters were: $\mathrm{TE}=40 \mathrm{~ms}$, $\mathrm{TR}=2 \mathrm{~s}, 64 \times 64$ matrix, interslice gap $=0.3 \mathrm{~mm}$, field-of-view $=200 \times 200 \mathrm{~mm}$ and flip angle $=90$. Stimulus presentation was synchronized with image acquisition via an optical relay, triggered by the radiofrequency pulse. Purpose-written software was used for synchronizing the presentation of stimuli, visual scale display, subject responses, and image acquisition.

Following fMRI scanning, high-resolution morphological data were acquired using an axial T1-3D spoiled gradient recalled acquisition in steady state sequence, with the following parameters: 124 slices $(1.5 \mathrm{~mm}$ thick $), \mathrm{TR}=20 \mathrm{~s}, \mathrm{TE}=3 \mathrm{~s}$, matrix $=256 \times 192$, field-of-view $=220 \mathrm{~mm}$, flip-angle $=20$; as well as a fluid-attenuated inversion recovery sequence aimed at excluding structural brain lesions (twenty $5 \mathrm{~mm}$-thick slices, TR $=10000 \mathrm{~ms}, \mathrm{TE}=140 \mathrm{~ms}, \mathrm{IR}=2200 \mathrm{~ms}$, field -of-view $=240 \mathrm{~mm}$ ).

Within five days before the fMRI session, subjects were trained in a sham session, lying down inside a scanner simulator that replicated the MRI environment and the sounds emitted during image acquisition. This procedure aimed to accustom the participants to the MR environment and to the task format used for eliciting emotional reactions, thus minimizing habituation effects over the three functional runs of the actual fMRI scanning session.

\section{Data analysis}

Image processing involved, firstly, data realignment to minimize motion-related artifacts, ${ }^{26}$ and Gaussian smoothing at FWHM = $7.2 \mathrm{~mm}$. Changes in blood oxygen level-dependent (BOLD) signals in association with each condition were modeled using the General Linear Model, assuming the haemodynamic response function as the convolution of experimental design by two gamma-variate functions ( 4 and 8 seconds after onset). The weighted sum of these two convolutions providing the best fit to the time series at each voxel was calculated, and a goodness of fit statistic (SSQ ratio) was computed at each voxel. ${ }^{27}$ The SSQ ratio is defined as the quotient between the sum of squares of residuals under constrained model (assuming there is no activation) and the sum of squares of residuals for the complete model. The SSQ ratio distribution under the null hypothesis (of no activation) was obtained by using wavelet-based permutation. ${ }^{27}$ This permutation approach has been shown to provide good Type I error control with minimal distributional assumptions.

In order to extend statistical inferences to the group level, the SSQ ratio maps were spatially normalized to Talairach standard space by first applying a rigid body transformation of the fMRI data into high-resolution morphological images of the same subjects, followed by an affine transformation onto a template. ${ }^{26}$ In order to identify voxel clusters showing significant BOLD response differences between conditions, the median differences of SSQ ratios over all subjects between conditions were initially tested at voxel-wise $\mathrm{p}$-values $<0.05$. The "activated" voxels were then assembled into $3 \mathrm{D}$-connected clusters and the sum of the SSQ ratios (statistical cluster mass) was determined for each cluster. The same procedure was repeated for the median SSQ ratio maps obtained by waveletpermutation of data for the specific scripts conditions, in order to compute the null distribution of statistical cluster masses under the null hypothesis. This distribution was then used to determine the critical threshold for the cluster mass under the null hypothesis at a Type I error level of cluster-wise p-value $<0.05$.

\section{Skin conductance response (SCR) acquisition and analysis}

Skin conductance signals were recorded simultaneously with fMRI acquisition, in order to provide objective measures of psychophysiological changes associated with the emotional reactions elicited by the presentation of scripts. Standard fingertip $\mathrm{AgCl}$ leads ${ }^{28}$ were placed on the middle phalanges of the index and middle fingers of the left hand. The electrode leads were connected through a high pass filter on the penetration panel to a SCR transducer connected to a stand-alone monitor unit $\left(\right.$ Psylab $\left.^{\circledR}\right)$ outside the scanner room. Analog signals were recorded at $100 \mathrm{~Hz}$, passed to an $\mathrm{AD}$ converter, and recorded using Psylab software $\left(\right.$ Psylab $\left.^{\circledR}\right)$, on a purpose-configured laptop. Measurements were expressed as the difference between the skin conductance level (SCL) obtained during the presentation of a given personal script and the respective baseline value. Runs during which the curves' variation in signal intensity was lower than $0.05 \mu S$ were discarded.

\section{Results}

\section{Subjective self-reported ratings of emotions}

Mean emotion intensity scores provided by subjects at the end of each condition are presented in Table 1 . As expected, there were significant differences in subjective scores for irritability across the four different conditions (baseline, happiness, irritability and neutral state), with subjects reporting feeling significantly more irritated immediately after presentation of the irritability scripts relative to all other conditions (Table 1). There were also significant differences in the subjective scores for sadness across conditions, with subjects showing higher sadness scores after presentation of the irritability scripts relative to all other conditions (Table 1). 
Table 1 - Subjective self-report ratings of emotions during each personal script presentation and the baseline condition $(n=11)$

\begin{tabular}{|c|c|c|c|c|c|c|}
\hline $\begin{array}{l}\text { Self-reported } \\
\text { emotions }\end{array}$ & $\begin{array}{l}\text { Mean (SD) scores } \\
\text { for irritability } \\
\text { scripts }\end{array}$ & $\begin{array}{l}\text { Mean (SD) scores } \\
\text { for happiness } \\
\text { scripts }\end{array}$ & $\begin{array}{l}\text { Mean (SD) scores } \\
\text { for personal } \\
\text { neutral scripts }\end{array}$ & $\begin{array}{l}\text { Mean (SD) scores } \\
\text { for the baseline } \\
\text { condition }\end{array}$ & $\begin{array}{c}\text { Chi-Square } \\
\quad \text { (df = 3; } \\
\text { Friedman Test) }\end{array}$ & p-value \\
\hline Irritability & $3.28(0.74)^{*}$ & $1.25(0.53)$ & $1.50(0.90)$ & $1.72(0.84)$ & 24.29 & $<0.001$ \\
\hline Sadness & $2.39(0.69)^{*}$ & $1.30(0.52)$ & $1.17(0.41)$ & $1.25(0.38)$ & 29.11 & $<0.001$ \\
\hline Happiness & $1.42(0.62)$ & $3.64(0.56)^{\star \star}$ & $2.56(0.82)^{\star \star \star}$ & $1.96(0.64)$ & 32.22 & $<0.001$ \\
\hline Anxiety & $2.22(0.74)$ & $2.39(1.12)$ & $2.56(0.82)$ & $2.03(1.09)$ & 5.79 & 0.122 \\
\hline Fear & $1.47(0.52)$ & $1.39(0.47)$ & $1.19(0.39)$ & $1.36(0.52)$ & 2.56 & 0.465 \\
\hline
\end{tabular}

* Significantly greater than the scores for the presentation of either personal neutral scripts, happiness scripts or the baseline condition $(p<$ 0.05 , Bonferroni Correction, post-hoc Wilcoxon tests).

** Significantly greater than the scores for the presentation of either irritability scripts, personal neutral scripts or the baseline condition $(p<0.05$, Bonferroni Correction, post-hoc Wilcoxon tests).

${ }_{* * *}$ Significantly greater than the scores for the presentation of irritability scripts $(p<0.05$, Bonferroni Correction, post-hoc Wilcoxon tests).

The comparison of STAI scores before and after the fMRI procedure did not show significant differences $(\mathrm{t}=1.04 ; \mathrm{df}=10$, $\mathrm{p}=0.325$, paired $\mathrm{t}$-test).

\section{Patterns of BOLD signal differences between conditions}

Results of the comparison of BOLD effects between the irritability, happiness and neutral conditions are displayed in Figure 1. Table 2 provides the coordinates for the voxels of maximal statistical significance in each cluster showing BOLD signal differences between conditions, as well as the size of those clusters and the corresponding statistical test values.

In the comparison of the irritability condition relative to the neutral condition, four foci of regional increases in BOLD effect in association with the irritability scripts were detected (Figure 1 and Table 2), located respectively in: the left subgenual anterior cingulate cortex (BA25) extending towards the left caudate nucleus; the left dorsomedial prefrontal cortex (BA9); the left

Table 2 - Location and statistical significance of foci of blood oxygen level dependent (BOLD) signal differences between the presentation of irritability, happiness and neutral scripts in healthy volunteers $(n=11)$

\begin{tabular}{|c|c|c|c|c|c|}
\hline \multirow{2}{*}{ Brain region (Brodmann Area - BA) } & \multicolumn{3}{|c|}{ Coordinates $(\mathrm{mm})$} & \multirow{2}{*}{$\begin{array}{l}\text { Cluster } \\
\text { p-value* }\end{array}$} & \multirow{2}{*}{$\begin{array}{c}\text { Size } \\
\text { (voxels) }\end{array}$} \\
\hline & $\mathbf{x}$ & $\mathbf{y}$ & $\mathbf{z}$ & & \\
\hline \multicolumn{6}{|l|}{ Irritability > Neutral } \\
\hline L Subgenual cingulate gyrus (BA25) / caudate nucleus & -14.4 & 14.8 & -12.6 & 0.020 & 25 \\
\hline L Dorsal posterolateral prefrontal/precentral cortex (BA44/4/6) & -43.3 & 11.1 & 25.8 & 0.007 & 57 \\
\hline L Dorsomedial prefrontal cortex (BA9) & -7.2 & 48.1 & 20.3 & 0.015 & 32 \\
\hline L Dorsal anterolateral prefrontal cortex (BA10) & -21.6 & 55.5 & 14.8 & 0.010 & 34 \\
\hline \multicolumn{6}{|l|}{ Irritability > Happiness } \\
\hline L Fusiform gyrus (BA37)/ cerebellum & -25.2 & -29.6 & -29.1 & 0.044 & 11 \\
\hline L Subgenual cingulate gyrus (BA25)/ caudate nucleus & -14.4 & 14.8 & -12.6 & 0.016 & 21 \\
\hline L Lingual gyrus (BA19) & -46.9 & -55.5 & -1.6 & 0.007 & 52 \\
\hline L Dorsomedial prefrontal cortex (BA9) & -14.4 & 51.8 & 14.8 & 0.048 & 10 \\
\hline L Dorsal anterolateral prefrontal cortex (BA10) & -25.2 & 51.8 & 14.8 & 0.017 & 17 \\
\hline \multicolumn{6}{|l|}{ Neutral > Irritability } \\
\hline R Temporal pole (BA38) & 39.7 & 11.1 & -29.1 & 0.016 & 18 \\
\hline L Inferior temporal gyrus (BA37) & -50.5 & -48.1 & -7.1 & 0.016 & 24 \\
\hline L Middle/ superior temporal gyri (BA21/22) & -57.7 & -22.2 & -7.1 & 0.005 & 34 \\
\hline R Middle temporal gyrus (BA21) & 50.5 & -14.8 & -12.6 & 0.047 & 11 \\
\hline L Hippocampus/ fusiform gyrus (BA66/37) & -39.7 & -40.7 & -7.1 & 0.019 & 18 \\
\hline L Fusiform gyrus (BA19) & -32.5 & -59.2 & 9.3 & 0.019 & 24 \\
\hline \multicolumn{6}{|l|}{ Happiness > Irritability } \\
\hline R Temporal pole (BA38) & 28.8 & -14.8 & -40.1 & 0.032 & 13 \\
\hline L Inferior/ middle temporal gyri (BA20/21/37) & -50.5 & -37.0 & -18.1 & 0.001 & 64 \\
\hline $\mathrm{R}$ Inferior / middle temporal gyri (BA20/21) / posterior insula & 46.9 & 0.0 & -23.6 & 0.005 & 55 \\
\hline L Hypothalamus/ thalamus & -7.2 & -7.4 & -7.1 & 0.035 & 19 \\
\hline L Anterior insula/dorsal posterolateral prefrontal cortex (BA44) & -43.3 & 3.7 & 14.8 & 0.024 & 17 \\
\hline
\end{tabular}

* Significance was set at cluster-wise p-value $<0.05 . L=$ left; $R=$ right. 
(a)

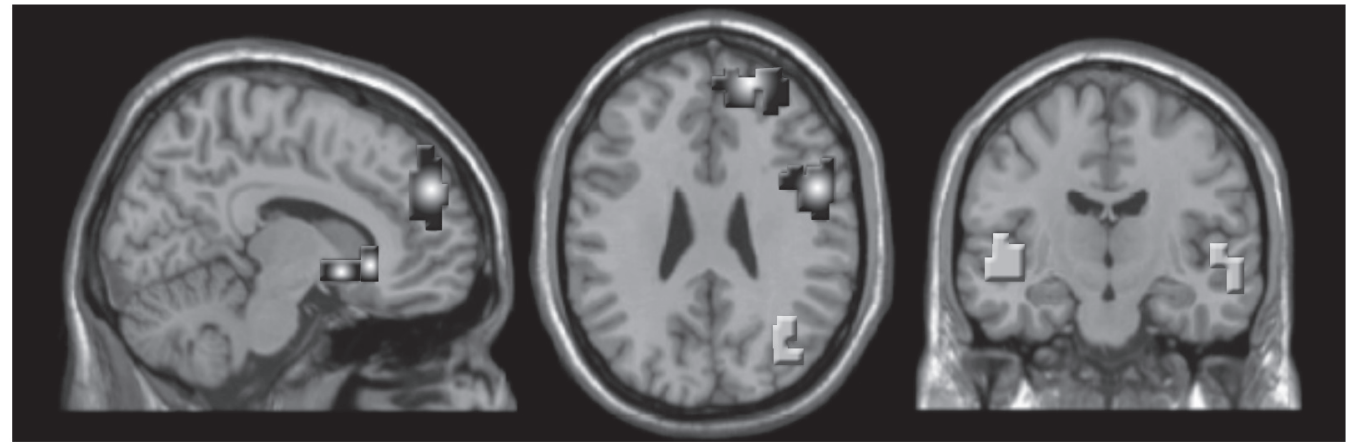

(b)

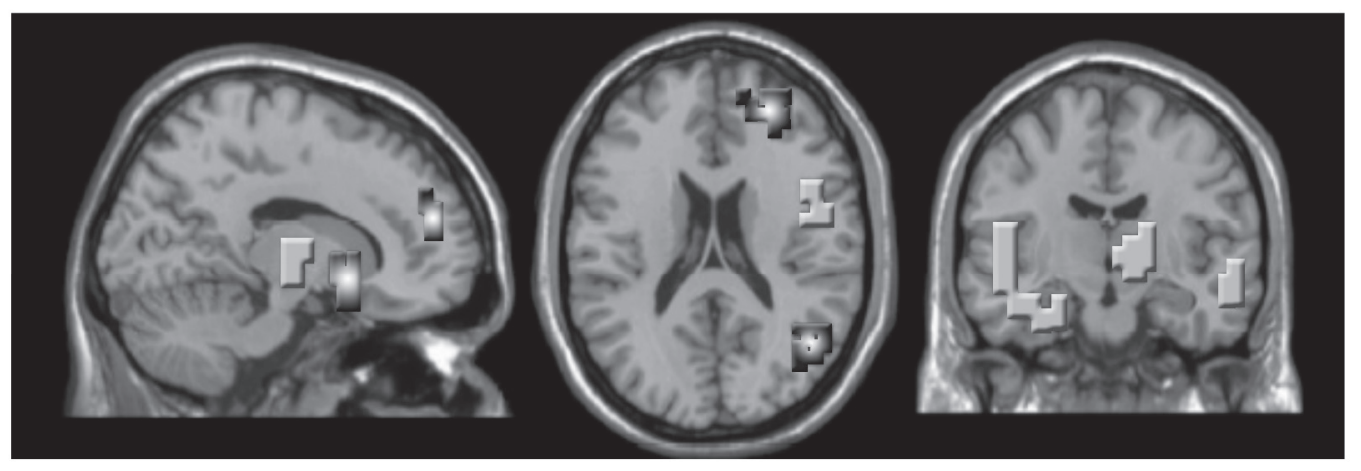

Figure 1 - Areas showing significant blood oxygen level dependent (BOLD) signal differences during irritability scripts relative to either emotionally neutral or happiness scripts (cluster-wise p-value $<0.05$ ) are highlighted in white to black colors (increased activity) and gray color (decreased activity). Foci of significance have been overlaid on a T1 morphometric template, and are displayed on selected sagital (left-hand frames), transaxial (middle frames) and coronal planes (right-hand frames). The right side of the transaxial and coronal images corresponds to the left side of the brain (radiological convention). In (a), foci of increased BOLD effect during irritability scripts compared to emotionally neutral scripts are shown on the left subgenual cingulate, dorsal anterolateral prefrontal, dorsomedial prefrontal and dorsal posterolateral prefrontal cortices, while areas of decreased BOLD effect are seen bilaterally on temporal lobe regions. In (b), clusters of increased BOLD effect during irritability scripts compared to happiness scripts are seen on the same subgenual cingulate and prefrontal regions shown above, with the exception of the left dorsal posterolateral prefrontal cortex; the foci of de-activation during irritability scripts were more extensive when compared to the happiness condition, involving not only the right and left temporal lobes but also the insula bilaterally, and the left thalamus and hypothalamus. The coordinates of voxels of maximal statistical difference between conditions in each cluster, as well as their sizes and significance, are provided in Table 2.

dorsal anterolateral prefrontal cortex (BA10); and the left dorsal posterolateral prefrontal cortex (BA44) extending towards the precentral gyrus (BA6/4).

The findings of the comparison of the irritability condition versus the happiness condition have been reported elsewhere. ${ }^{15}$ These results are presented again here, as this contrast is relevant to the delineation of the brain activity patterns specifically related to the emergence of irritability, as opposed to an emotional reaction of positive valence. When contrasted with the happiness condition, the presentation of irritability scripts was associated with increased BOLD signal in similar locations as described in the paragraph above (Figure 1 and Table 2), including the left subgenual anterior cingulate gyrus (BA25) extending towards the left head of the caudate nucleus, the dorsal anterolateral prefrontal cortex (BA10), and the dorsomedial prefrontal cortex (BA9). However, the focus of increased BOLD signal in the left dorsal posterolateral prefrontal cortex (BA44) was no longer present. In addition, this contrast showed activation of the left cerebellum and fusiform/lingual gyri (BA19/37) in association with the irritability condition (Table 2 ).

Areas of decreased BOLD effect during the irritability condition relative to the presentation of neutral scripts (Figure 1 and Table 2) were seen mainly in the temporal and occipital areas, including the right middle temporal gyrus (BA21), left middle and superior temporal gyri (BA21/22), right temporal pole (BA38), left inferior temporal gyrus (BA20/37), left fusiform gyrus (BA19/37), and left hippocampus (BA66). Relative to the happiness scripts, the irritability condition was also associated with temporal lobe areas of decreased BOLD signal, involving the right temporal pole (BA38), right inferior and middle temporal gyri extending to the posterior insula (BA20/21), and the left inferior and middle temporal gyri (BA20/21/37). There were also foci of decreased BOLD signal during irritability relative to happiness scripts in the left anterior insula extending to the dorsal postero-lateral prefrontal cortex (BA44), as well as in the left thalamus and hypothalamus (Table 2). 


\section{Skin conductance levels}

The SCR measures of 3 subjects had to be discarded, due to variation in signal intensity lower than $0.05 \mu \mathrm{S}$. The results for the remaining 8 subjects, over the three runs, are presented in Table 3. Mean scores for the SCL difference relative to the baseline condition were positive for the three types of scripts, showing that all of those personal script conditions were associated with greater SCR in comparison to the baseline state. Regardless of the type of condition, there was an overall tendency towards lower values from the first to the third run. A trend towards significant differences between conditions was seen during the first run, with a tendency to lower irritability SCL values relative to both happiness and neutral script values (Table 3).

\section{Discussion}

To the best of our knowledge, this is the first fMRI study to have used autobiographical scripts to investigate the brain circuitry involved in the mediation of irritability states in healthy subjects. There were significant differences in self-reported ratings of subjective emotions across the irritability, happiness and emotionally neutral conditions, as well as a trend towards differences in skin conductance levels, thus suggesting that the paradigm was successful in eliciting distinct emotional states. When the irritability condition was contrasted against either the happiness condition or the emotionally neutral control state, significant differences in BOLD signal were detected in a limited set of brain regions. These changes included increased activity in the subgenual anterior cingulate cortex and specific portions of the dorsal prefrontal cortex, as well as decreased activity in inferior temporal regions.

We detected a focus of significant left subcallosal cingulate activation during the irritability condition relative to both the happiness and emotionally neutral states. Contemporary models of emotional processing place the subgenual cingulate cortex as an important component of a ventral neuronal network that is critical to the actual generation of normal and pathological emotional states, as well as to the automatic regulation of autonomic responses in the context of those states. ${ }^{2,3}$ Using this type of autobiographical recall paradigm, we found activation of the subgenual cingulate cortex during presentation of irritability scripts but not during presentation of happiness scripts. ${ }^{15}$ This distinction supports the view that the engagement of this brain region is more closely related to the generation of negative rather than positive emotions. ${ }^{1}$ It is also interesting that the pattern of subcallosal cingulate cortical activation reported here, together with the de-activation of inferior temporal regions, resembles the results of previous imaging studies that investigated the brain circuits involved in normal sadness or major depression. ${ }^{1,2,29,30}$ Despite the lack of universal agreement, there have been propositions that the activation of the subgenual cingulate cortex could be a specific feature linked to the generation of normal and pathological sadness. ${ }^{1-3}$ Thus the engagement of the subgenual cingulate cortex in our study could be due to the fact that the presentation of irritability scripts elicited significant feelings not only of irritability, but also of sadness. Such overlap between irritability and sadness is consistent with the recognized relevance of irritability emotions to the clinical profile of depressive disorders. ${ }^{11,12}$ Also, recent imaging studies have suggested the involvement of the subgenual cingulate cortex, together with prefrontal areas, in the neurobiology of bipolar disorder ${ }^{31}$ and manic and hypomanic states. ${ }^{32}$ These findings may suggest that the abnormal functioning of the brain regions implicated herein could be related to the expression of irritability not only in the context of depression, but also in that of manic and/or mixed states. ${ }^{14}$

The pattern of increased activity in the BA 9 portion of the left dorsomedial prefrontal cortex, which was present during the presentation of irritability scripts relative to the neutral emotional state, is unlikely to be specifically related to the emergence of irritability emotions. This portion of the frontal lobe has been engaged in several studies that used autobiographical scripts to elicit different kinds of emotion, both of negative and positive valence. ${ }^{1,4}$ The lack of specificity of left dorsomedial prefrontal activation to the irritability condition is confirmed by the fact that the use of this paradigm during presentation of happiness scripts elicits increased activity in this prefrontal region relative to the presentation of neutral scripts, as we reported previously. ${ }^{15}$ There has been a high degree of consistency in the engagement of the dorsomedial prefrontal cortex during performance of emotion-related paradigms in functional neuroimaging studies, using not only autobiographical scripts but also other forms of stimulation. ${ }^{1,33-35}$ This has supported the notion of a general role for this brain region in emotional processing, possibly related to the interoceptive awareness of emotions, and the conscious regulation of emotional arousal and autonomic responses. ${ }^{1,2,4}$

One feature specifically related to the emergence of irritability in our study was the pattern of increased activity in the left anterior dorsolateral prefrontal cortex (BA10), which was not engaged during the happiness condition relative to the neutral state, as we reported previously. ${ }^{15}$ It has been suggested that the involvement

Table 3 - Mean difference for the scores (and standard deviation) of skin conductance level between each personal script condition and the respective baseline period $(n=8)$

\begin{tabular}{lccc}
\hline & First run & Second run & Third run \\
\hline Irritability condition & $0.169(0.257)^{*}$ & $0.058(0.078)$ & $0.030(0.090)$ \\
Happiness condition & $0.034(0.064)$ & $0.107(0.095)$ & $0.016(0.058)$ \\
Neutral condition & $0.036(0.124)$ & $0.098(0.094)$ & $0.020(0.052)$ \\
Friedman test p-value [Chi-square; df] & $0.072[5.250 ; 2]$ & $0.093[4.750 ; 2]$ & $0.882[0.250 ; 2]$ \\
\hline
\end{tabular}

* Trend towards significantly lower values compared either to the happiness $(p=0.093)$ or neutral $(0.069)$ script conditions (post-hoc Wilcoxon tests). 
of specific dorsolateral prefrontal regions in functional imaging studies of emotional processing in humans could vary as a function of the valence of the specific emotions evaluated in each study. ${ }^{1}$ However, it is unlikely that the differential involvement of the anterior dorsolateral prefrontal cortex (BA10) between the irritability and happiness conditions in our investigation would have been determined simply by the opposite valence of those two emotional states; studies using experimental designs to specifically address this issue have suggested a greater involvement of the left anterior dorsolateral prefrontal cortex in direct proportion to the degree of positive valence of the emotional response evaluated. ${ }^{33}$ Also, it is unlikely that the engagement of the anterior dorsolateral prefrontal cortex would have been influenced by the emergence of sadness during the presentation of irritability scripts; previous functional imaging studies of normal or pathological sadness have actually shown decreased rather than increased activity of the prefrontal cortex in association with the emergence of the latter kind of emotion. ${ }^{29}$

One other possibility, which is in accordance with the predictions of our study, is that the engagement of the anterior dorsolateral prefrontal cortex would have been determined by the salience of cognitive-related aspects during the stimulation paradigm. Such engagement could, for instance, be related to the role of the anterior dorsolateral prefrontal cortex in the retrieval of personal memories and/or the attention being paid to one's own emotions. ${ }^{36}$ This would not be sufficient, however, to explain the more extensive activation in the anterior portions of the dorsolateral prefrontal cortex specifically during the irritability condition, as subjects were able to recall autobiographical events and re-experience equally the emotions of irritability and happiness during the respective scripts, as attested by the high subjective rating scores given for those two emotions during both conditions. On the other hand, previous PET and fMRI studies of healthy subjects have consistently shown the engagement of the anterior dorsolateral prefrontal cortex during the performance of cognitive tasks involving aspects other than autobiographical and longterm episodic memory, such as executive functioning/working memory. ${ }^{34,35}$ Taking into account the latter imaging findings and those of lesion studies, current models of emotional processing have implicated dorsolateral prefrontal regions as critical to the cognitively effortful regulation of emotional states. ${ }^{2,4}$ This proposition is entirely consistent with the relevance attributed to cognitive aspects in current conceptualizations of irritability. ${ }^{8}$ In this context, a robust engagement of anterior dorsolateral prefrontal portions specifically during the emergence of irritability emotions could be related to the use of cognitive-based strategies aimed at, for instance, re-evaluating the magnitude of the emotional response in the face of the stimuli that elicited irritability, or appraising the potentially adverse social consequences that might follow if aggressive reactions were to be expressed in response to such stimuli.

One additional aspect that suggests a salience of cognitive control strategies particularly during the presentation of irritability scripts is the tendency that we found towards lower SCL during the irritability condition compared to during the presentation of neutral scripts (specifically during the first fMRI run). ${ }^{15}$ Recent fMRI studies have shown SCR decrements (in direct proportion to increased BOLD signal in the prefrontal cortex) when cognitive effortful processing aspects are added to emotion-provoking paradigms in healthy humans. ${ }^{28,37}$

The above arguments favor the view that the increased anterior prefrontal activity that we found during the processing of irritability emotions would be specifically related to cognitive regulation strategies.

This hypothesis should be evaluated in future studies directly comparing the construct of irritability with other negative emotions that supposedly lack such cognitive control aspects, including anger and sadness. Also, imaging studies directly comparing anger and irritability conditions would be desirable, to clarify other issues raised by the present investigation. For instance, the activation patterns obtained during the induction of irritability were distinct from the findings of previous brain imaging studies that investigated the functional circuitry underlying the induction of anger: in PET and fMRI studies using autobiographical scripts of anger experiences, ${ }^{24}$ healthy subjects consistently display increased activation of the orbitofrontal cortex, and also often engage the rostral anterior cingulate gyrus and the temporal pole. In the present study, rather than activation of the orbitofrontal cortex or the temporal pole, we actually detected a site of de-activation of the right temporal pole. If confirmed in subsequent studies directly comparing irritability and anger, the lack of activation of the functional circuitry seen as critical to the processing of anger may indicate that irritability and anger emotions can be distinguished from each other not only in terms of psychopathological characteristics, ${ }^{6-8}$ but also in regard to their underlying brain mechanisms.

Finally, one finding not consistent with our initial predictions was the attenuation of BOLD signal in the anterior and posterior insula during the irritability condition relative to the happiness state. The insula is thought to be relevant to the cortical mapping of information pertaining to bodily responses that accompany emotional reactions. ${ }^{38}$ Our pattern of results indicates that, during paradigms of autobiographical recall, emotions of positive valence may elicit greater activity increases in brain regions involved in the central mapping of emotion-based somatic markers than emotions of negative valence.

The interpretation of the findings reported here has to be made with caution, due to several limitations of our study. The size of the sample was modest, and the inclusion of both males and females may have increased the variability of regional brain activity measurements during emotional processing. Also, the gradient EPI protocol employed may be subject to susceptibility-induced signal losses and geometric distortions that could complicate the assessment of brain areas thought to be relevant for the processing of negative emotions, such as the orbitofrontal cortex and amygdala. ${ }^{39,40}$ However, it should be mentioned that we did detect signal changes in other brain regions that would have 
been equally susceptible to those artifacts, such as the temporal poles. Nevertheless, replication of our findings is warranted using optimized EPI protocols aimed at improving the signal sensitivity in brain regions subject to susceptibility-induced artifacts. Finally, it should be mentioned that the pattern of brain activity changes during irritability provocation may be specific to the induction method that we have used. For instance, studies investigating other emotions have found that the amygdala is not engaged when emotional states are induced by internally/cognitively-generated imagery recall as in our paradigm, ${ }^{29}$ but may respond robustly when emotions are induced by externally-cued perceptual stimuli. ${ }^{1}$

\section{Conclusion}

Our study provided evidence that the induction of irritability, using autobiographical scripts, elicits functional activity changes in several brain regions thought to be critical both to the generation and to the cognitive control of emotional states. There were changes in BOLD signal in the prefrontal cortex, subgenual anterior cingulate gyrus and inferior temporal neocortex, all of which have been previously implicated in the emergence and/or autonomic regulation of negative emotions. Also, we detected specific foci of significantly increased activity in anterior dorsolateral prefrontal areas, which are most probably related to the cognitively effortful modulation and management of the irritability reaction. If replicated in subsequent studies, these findings may provide a basis for future investigations aimed at delineating the dysfunctional brain circuits that mediate the processing of irritability reactions in pathological mood conditions, of depressive, manic or mixed nature.

\section{Acknowledgements}

We are indebted to Antonio Cesário da Cruz for his invaluable help in synchronizing data acquisition and simulations, and for manufacturing the devices used in the study. We also thank Maria Angela Barreiros and Fábio G. Barros for assistance in the process of image acquisition and analysis; Chris M. Andrew and David J. Gasston for their contribution in adapting skin conductance recording to the MRI environment; Fabio Luiz de Souza Duran for help in the production of illustrations; Luciana Santos for assistance in the preparation of the manuscript; and Pérola Paes, Guilherme Maciel and Oswaldo Siman for the production of narrative scripts.

\section{Disclosures}

\begin{tabular}{|c|c|c|c|c|c|c|c|}
\hline $\begin{array}{l}\text { Writing group } \\
\text { member }\end{array}$ & Employment & $\begin{array}{l}\text { Research } \\
\text { grant }^{1}\end{array}$ & $\begin{array}{l}\text { Other research grant or } \\
\text { medical continuous } \\
\text { education }^{2}\end{array}$ & $\begin{array}{l}\text { Speaker's } \\
\text { honoraria }\end{array}$ & $\begin{array}{c}\text { Ownership } \\
\text { interest }\end{array}$ & $\begin{array}{l}\text { Consultant } / \\
\text { Advisory } \\
\text { board }\end{array}$ & Other ${ }^{3}$ \\
\hline $\begin{array}{l}\text { Carlos T. } \\
\text { Cerqueira }\end{array}$ & - & - & * & - & - & - & CNPq \\
\hline $\begin{array}{l}\text { Jorge R. C. } \\
\text { Almeida }\end{array}$ & - & - & - & - & - & - & - \\
\hline João R. Sato & UFABC & - & - & - & - & - & - \\
\hline $\begin{array}{l}\text { Clarice } \\
\text { Gorenstein }\end{array}$ & FMUSP & FAPESP & - & - & - & - & - \\
\hline Valentim Gentil & FMUSP & FAPESP & Novartis $^{\star \star}$ & $\begin{array}{c}\text { Janssen** } \\
\text { Lilly } \\
\text { Servier }\end{array}$ & - & Servier & - \\
\hline Claudia C. Leite & FMUSP & - & - & - & - & - & - \\
\hline Edson Amaro Jr & FMUSP & $\begin{array}{c}\text { CAPES }^{* *} \\
\text { CNPq } \\
\text { FAPESP }\end{array}$ & - & - & - & - & - \\
\hline $\begin{array}{l}\text { Geraldo F. } \\
\text { Busatto }\end{array}$ & FMUSP & $\begin{array}{l}\text { FAPESP }^{* *} \\
\text { CNPq }\end{array}$ & - & - & - & - & - \\
\hline
\end{tabular}

${ }^{*}$ Modest

** Significant

*** Significant: Amounts given to the author's institution or to a colleague for research in which the author has participation, not directly to the author.

Note: UFABC = Universidade Federal do ABC; FMUSP = Faculdade de Medicina, Universidade de São Paulo; FAPESP = Fundação de Amparo à Pesquisa do Estado de São Paulo; CAPES = Coordenação de Pessoal de Nivel Superior; $C N P q=$ Conselho Nacional de Desenvolvimento Científico e Tecnológico.

For more information, see Instructions for authors.

References

1. Phan KL, Wager T, Taylor SF, Liberzon I. Functional neuroanatomy of emotion: a meta-analysis of emotion activation studies in PET and fMRI. Neuroimage. 2002;16(2):331-48.

2. Phillips ML, Drevets WC, Rauch SL, Lane R. Neurobiology of emotion perception I: The neural basis of normal emotion perception. Biol Psychiatry. 2003;54(5):504-14.
3. Phillips ML, Drevets WC, Rauch SL, Lane R. Neurobiology of emotion perception II: Implications for major psychiatric disorders. Biol Psychiatry. 2003;54(5):515-28.

4. Phillips ML, Ladouceur CD, Drevets WC. A neural model of voluntary and automatic emotion regulation: implications for understanding the pathophysiology and neurodevelopment of bipolar disorder. Mol Psychiatry. 2008;13(9):833-57. 
5. Buss A, Durkee A. An inventory for assessing different kinds of hostility. $J$ Consult Clin Psychol. 1957;21(4):343-9.

6. Snaith RP, Taylor CM. Irritability: definition, assessment and associated factors. BrJ Psychiatry. 1985;147:127-36.

7. Moyer KE. The psychology of aggression. London: Harper \& Row; 1976.

8. Giancola PR. Irritability, acute alcohol consumption and aggressive behavior in men and women. Drug Alcohol Depend. 2002;68(3):263-74.

9. Gorenstein C, Gentil V, Melo M, Lotufo-Neto F, Lauriano V. Mood improvement in 'normal' volunteers. J Psychopharmacol. 1998;12(3):246-51.

10. Meyer TD, Hautzinger M. The structure of affective symptoms in a sample of young adults. Compr Psychiatry. 2003;44(2):110-6.

11. American Psychiatric Association. Diagnostic and Statistical Manual of Mental Disorders (DSM-IV). 4th ed. Washington, DC: American Psychiatric Association; 1994.

12. Perlis RH, Fraguas R, Fava M, Trivedi MH, Luther JF, Wisniewski SR, Rush AJ. Prevalence and clinical correlates of irritability in major depression disorder: a preliminary report from the sequenced treatment alternatives to relieve depression study. J Clin Psychiatry. 2005;66(2):159-66.

13. Deckersbach T, Perlis RH, Frankle WG, Gray SM, Grandin L, Dougherty DD, Nierenberg AA, Sachs GS. Presence of irritability during depressive episodes in bipolar disorder. CNS Spectr. 2004;9(3):227-31.

14. Benazzi F, Akiskal H. Irritable-hostile depression: further validation as a bipolar depressive mixed state. J Affect Disord. 2005;84(2-3):197-207.

15. Cerqueira CT, Almeida JRC, Gorenstein C, Gentil V, Leite CC, Sato JR, Amaro E Jr, Busatto GF. Engagement of multifocal neural circuits during recall of autobiographical happy events. BrazJ Med and Biol Res. 2008;41(12):1076-85.

16. Wager TD, Davidson ML, Hughes BL, Lindquist MA, Ochsner KN. Prefrontalsubcortical pathways mediating successful emotion regulation. Neuron. 2008;59(6):1037-50.

17. Oldfield RC. The assessment and analysis of handedness: the Edinburgh inventory, Neuropsychologia. 1971;9(1):97-113.

18. Spitzer RL, Williams JB, Gibbon M, First MB. The Structured Clinical Interview for DSM-III-R (SCID). I: History, rationale, and description. Arch Gen Psychiatry. 1992;49(8):624-9.

19. Weissman MM, Wickramaratne P, Adams P, Wolk S, Verdeli H, Olfson M. Brief screening for family psychiatric history: the family history screen. Arch Gen Psychiatry. 2000;57(7):675-82.

20. Kanner AD, Coyne JC, Schaefer C, Lazarus RS. Comparison of two modes of stress measurement, daily hassles and uplifts versus major life events. J Behav Med. 1981;4(1):1-39.

21. George MS, Ketter TA, Parekh PI, Herscovitch P, Post RM. Gender differences in regional cerebral blood flow during transient self-induced sadness or happiness. Biol Psychiatry. 1996;40(9):859-71.

22. Campos A, Amor A, Gonzalez MA. Presentation of keywords by means of interactive drawings. Span J Psychol. 2002;5(2):102-9.

23. Pitman RK, Orr SP, Forgue DF, de Jong JB, Claiborn JM. Psychophysiologic assessment of posttraumatic stress disorder imagery in Vietnam combat veterans. Arch Gen Psychiatry. 1987;44(11):970-5.

24. Dougherty DD, Shin LM, Alpert NM, Pitman RK, Orr SP, Lasko M, Macklin ML, Fishman AJ, Rauch SL. Anger in healthy men: A PET study using script-driven imagery. Biol Psychiatry. 1999;46(4):466-72.

25. Spielberger CD, Gorsuch RL, Lushene RE. Manual for the State-Trait Anxiety Inventory. Palo Alto: Consulting Psychologists Press; 1970.

26. Bullmore ET, Fadili J, Breakspear M, Salvador R, Suckling J, Brammer MJ. Wavelets and statistical analysis of functional magnetic resonance images of the human brain. Stat Methods Med Res. 2003;12(5):375-99.

27. Friman O, Borga M, Lundberg P, Knutsson H. Adaptive analysis of fMRI data. Neuroimage. 2003;19(3):837-45.

28. Williams LM, Phillips ML, Brammer MJ, Skerrett D, Lagopoulos J, Rennie C, Bahramali H, Olivieri G, David AS, Peduto A, Gordon E. Arousal dissociates amygdala and hippocampal fear responses: evidence from simultaneous fMRI and skin conductance recording. Neuroimage. 2001;14(5):1070-9.

29. Mayberg HS, Liotti M, Brannan SK, McGinnis S, Mahurin RK, Jerabek PA, Silva JA, Tekell JL, Martin CC, Lancaster JL, Fox PT. Reciprocal limbic-cortical function and negative mood: converging PET findings in depression and normal sadness. Am J Psychiatry. 1999;156(5):675-82.

30. Chen CH, Ridler K, Suckling J, Williams S, Fu CH, Merlo-Pich E, Bullmore E. Brain imaging correlates of depressive symptom severity and predictors of symptom improvement after antidepressant treatment. Biol Psychiatry. 2007;62(5):407-14.
31. Monkul ES, Malhi GS, Soares JC. Anatomical MRI abnormalities in bipolar disorder: do they exist and do they progress? Aust $N Z J$ Psychiatry. 2005;39(4):222-6.

32. Lennox BR, Jacob R, Calder AJ, Lupson V, Bullmore ET. Behavioural and neurocognitive responses to sad facial affect are attenuated in patients with mania. Psychol Med. 2004;34(5):795-802.

33. Grimm S, Schmidt CF, Bermpohl F, Heinzel A, Dahlem Y, Wyss M, Hell D, Boesiger P, Boeker H, Northoff G. Segregated neural representation of distinct emotion dimensions in the prefrontal cortex-an fMRI study. Neuroimage. 2006;30(1):325-40.

34. Cabeza R, Nyberg L. Imaging cognition II: An empirical review of 275 PET and fMRI studies. J Cogn Neurosci. 2000;12(1):1-47.

35. Collette F, Van der Linden M, Laureys S, Delfiore G, Degueldre C, Luxen A, Salmon E. Exploring the unity and diversity of the neural substrates of executive functioning. Hum Brain Mapp. 2005;25(4):409-23.

36. Gilbert SJ, Spengler S, Simons JS, Steele JD, Lawrie SM, Frith CD, Burgess PW. Functional specialization within rostral prefrontal cortex (Area 10): a meta-analysis. J Cogn Neurosci. 2006;18(6):932-48.

37. Hariri AR, Mattay VS, Tessitore A, Fera F, Weinberger DR. Neocortical modulation of the amygdala response to fearful stimuli. Biol Psychiatry. 2003;53(6):494-501.

38. Critchley HD. Neural mechanisms of autonomic, affective and cognitive integration. J Comp Neurol. 2005;493(1):154-66.

39. Posse S, Fitzgerald D, Gao K, Habel U, Rosenberg D, Moore GJ, Schneider F. Real-time fMRI of temporolimbic regions detects amygdala activation during single-trial self-induced sadness. Neuroimage. 2003;18(3):760-8.

40. Cusack R, Russell B, Cox SM, De Panfilis C, Schwarzbauer C, Ansorge R. An evaluation of the use of passive shimming to improve frontal sensitivity in fMRI. Neuroimage. 2005;24(1):82-91. 